\title{
The Status of Quality of Life and Adaptation of Patients with Heart Failure to Their Disease in Shushtar, Khuzestan Province
}

\author{
Akram Mansouri, ${ }^{1}$ Shahram Baraz, ${ }^{1,}$ Nasrin Elahi, ${ }^{1}$ Mojtaba Miladinia, ${ }^{1}$ and Amal Saki Malehi ${ }^{2}$ \\ ${ }^{1}$ Nursing Care Research Center in Chronic Diseases, School of Nursing and Midwifery, Ahvaz Jundishapur University of Medical Sciences, Ahvaz, IR Iran \\ ${ }^{2}$ Health Research Institute, Thalassemia and Hemoglobinopathy Research Center, AhvazJundishapur University of Medical Sciences, Ahvaz, IR Iran \\ "Corresponding author: Shahram Baraz, Nursing Care Research Center in Chronic Diseases, School of Nursing and Midwifery, Ahvaz Jundishapur University of Medical \\ Sciences, Ahvaz, IR Iran. Fax: +98-6133738333, E-mail: shahrambaraz@ajums.ac.ir
}

Received 2016 April 13; Revised 2016 May 15; Accepted 2016 May 27.

\begin{abstract}
Background: Currently, studying the quality of life of patients and the level of their adaptation to their disease is considered an important issue in studies of chronic diseases. Heart failure affects the quality of life of patients in varying degrees.

Objectives: The present study aimed to determine the status of quality of life of patients with heart failure and their level of adaptation to their disease.

Methods: In this descriptive-analytical study, 76 patients with heart failure who had referred to one of the specialized therapy clinics of Shushtar in Khuzestan Province during year 2015 were selected based on the convenience sampling method and inclusion criteria. The research tools for collecting the required data and information included demographic information questionnaire, minnesota quality of life questionnaire, and an assessment form designed for patients with heart failure based on four dimensions of the Roy adaptation model. The data were analyzed using descriptive and analytical statistics (independent t-test).

Results: The results of this study showed that this disease leaves the greatest negative impact on the physical dimension of quality of life (32.97 \pm 6.89$)$. In addition, this disease has put the least negative impact on mental dimension of quality of life. Also, the lowest average adaptation was related to the dependence-independence dimension (28.71 \pm 5.54$)$. The results indicated that there is a significant difference between males and females in terms of physical and mental dimensions of quality if life, with lower averages of both in females $(\mathrm{P}=0.037$ and $\mathrm{P}=0.007$, respectively). The study findings also showed that different dimensions of adaptation are the same in males and females and there is no significant difference between them $(P>0.05)$.

Conclusions: The present study showed that quality of life and adaptation have a weak status in the studied patients with heart failure. By taking appropriate measures and training programs, nurses can help these patients improve their quality of life and level of adaptation to their disease.
\end{abstract}

Keywords: Heart Failure, Quality of Life, Adaptation, Chronic Illness

\section{Background}

Heart failure is a complex and chronic clinical syndrome in which the heart is not able to pump the blood required for metabolic needs of body due to ventricular dysfunction. With an annual high incidence of approximately 550,000 new cases per year, this disease has been introduced as a new epidemic (1). Incidence and prevalence of heart failure are increasing even in developed countries of the world (2). The hospitalization rate for this disease has increased to twice its original amount in the past two decades (3), and it is now one of the major causes of death (4). In Iran, over one million people are afflicted with heart failure (5). The prevalence of this disease in Iran has been reported to be $8 \%$, with the highest values in Khuzestan and Guilan provinces (6). Patients with heart failure undergo many problems such as shortness of breath, edema, pain, depression, fatigue, nausea, constipation, sleep disorders and anxiety (7). These problems could affect the activity, abilities, and strength levels of these patients (3). Coping with these debilitating symptoms often causes stress, low self-confidence and reduced quality of life (8), and also imposes a heavy financial burden on health care providers (9).

On the other hand, major physical changes caused by heart failure can affect the body image of patients and thus affect their behaviors. Negative feelings by threatening self-stability, arising from changes in routine life because of following specific instructions for heart failure patients may lead to poor adherence to and observance of medical instructions and finally re-hospitalization and low quality of life in these patients. In contrast, positive feelings by challenging self-stability, resulting from patient's efforts to restore their routine of life and cope with the illness, lead to higher adherence and observance of medical instructions, reduce the risk of re-hospitalization, and promote the quality of life in these patients (10). Quality of life is considered one of the most important objectives in 
health systems, especially in chronic and highly-prevalent diseases $(11,12)$. With the advancement in the treatment of heart diseases, longevity of patients with heart failure has increased and, as a result, improved quality of life has become more important for them. Studies conducted on health-related quality of life in chronic diseases indicate the adverse effects of diseases on physical, mental and social performance of patients $(1,13)$.

This chronic disease also negatively affects everyday life and can affect various aspects of life and lead to problems in coping with the disease. These patients usually show moderate or weak adaptation (14). Patients with heart failure lose their independence for doing their usual activities of life and rely on others. The main outcome of this disease is disorder in functional abilities and limitations in job, family, and social duties that finally lead to declined quality of life, social isolation, and depression, affecting the process of adaptation (1). In fact, symptoms of the disease and its complications over time cause limitations in routine life and adaptation of patients and affect their quality of life. As a result, the risk of re-hospitalization increases and more complications would appear (15).

The results of a study conducted by Shojaei showed that heart failure has negative effects on patients' quality of life, thus investigation and improvement of the quality of life of these patients should be regarded as one of the duties of nurses (15). The findings of Khalilzadeh et al. revealed that poor adaptation of patients to heart failure and the resulting problems lower their quality of life (16).

For improvement of ventricular pump function and reduction of myocardial workload, these patients need to reduce the physical-mental stresses and try to adapt with their disease. The findings suggest that $56.6 \%$ of patients with heart failure are not able to perform self-care and control the emotions caused by the disease. Nurses should encourage patients with heart failure to gradually do their daily activities and quickly adapt themselves with their disease (16). Given the importance of this issue, nurses, as important members of the health team, should understand the emotional responses of patients to their disease. Nurses should also receive appropriate trainings on this disease and its problems, treatment and side effects, diet, activities, and so on, in order to support patients in the process of adapting to their disease.

The Roy adaptation model in nursing extensively and deeply deals with physical and mental adaptation in chronic diseases. This model is a useful framework for collecting information from patients. The use of this model can effectively centralize, organize and guide the thoughts and actions of nurses (14). According to this model, nurses systematically and accurately examine the patients through interview, observation and measurement, and then determine the maladaptive behaviors that are patients' problems in four dimensions along with the drivers of behavior (reasons). Finally, detailed training and care programs will be developed for resolving the problems (14). The findings of another study suggested that the Roy adaptation model could be used as a guideline for investigation of adaptation processes (17). A study conducted by Khalilzadeh et al. showed that adaptation of patients to heart failure is at a poor level because of their lack of awareness about the nature of this disease, treatment methods, treatment regimens, and problems of this disease (16).

Given the prevalence of heart diseases and expansion of heart failure and its devastating effects on patients' quality of life, considering the high prevalence of this disease in Khuzestan province and hot weather of this region and its undeniable impact on mood, behaviors and adaptation of patients to heart failure, and regarding the multiethnic population of Khuzestan and existence of different cultures and lifestyles in this region and that no study has addressed this subject in Khuzestan province, the author decided to carry out a research in order to study the status of quality of life in patients with heart failure and the level of their adaptation to the disease. Hence, this study was the first investigation about this subject in Khuzestan province. For taking corrective actions to increase adaptation and improve the quality of life in these patients, basic information on the status of heir adaptation and quality of life are required in order to develop suitable programs for them according to their problems in each of the dimensions.

\section{Objectives}

The primary objective of this study was to determine the status of quality of life in patients with heart failure and the level of their adaptation to their disease. The secondary objective was to study the relationship of quality of life and adaptation with gender.

\section{Methods}

\subsection{Study Design and Population}

The present research was a cross-sectional study, which aimed to determine the status of quality of life and level of adaptation among patients with heart failure referred to one of the specialized therapy clinics of Shushtar in Khuzestan Province, during year 2015. During the research period (12 months), 121 patients referred to the selected center, 83 of whom met the inclusion criteria and finally 76 patients were selected as the sample based on the convenience sampling method. 
Inclusion criteria were: 1 ) elapse of at least six months from diagnosis; 2) patients with heart failure class 1,2 or 3 according to the America heart association; 3 ) an EF of $40 \%$ or lower; 4 ) being in the age range of 18 to 65 . Exclusion criteria were: 1) affliction with other chronic diseases such as kidney or liver failure, obstructive pulmonary disease, neuromotor disorders, etc. (except diabetes); 2) having a history of mental disorders; 3 ) not having the ability of walking.

\subsection{Measuring Tools}

The research tools for collecting the required data and information included demographic information questionnaire, Minnesota quality of life questionnaire, and an assessment form designed for patients with heart failure based on four dimensions of the Roy adaptation model. The data were collected through interviewing the patients or reviewing their medical records. Also, the left ventricular ejection fraction was extracted based on echocardiography results. In the present study, the ejection fraction was equal to or less than $40 \%$ based on echocardiography result in the medical records, which was regarded as heart failure. Minnesota quality of life questionnaire reflects patients' understanding of the effects of heart failure on physical, mental, economic and social aspects of their life. Items of this questionnaire were about symptoms of disease such as shortness of breath, fatigue, peripheral edema and sleep disorders, and psychiatric symptoms included depression and anxiety, social relations, physical and sexual activity, work, and emotions. Minnesota quality of life questionnaire consists of 21 items, with each scored based on Likert's five-point scale ( 0 = never, 1 = very little, 2 = little, 3 = moderate, $4=$ high, and $5=$ very high). The minimum (0) and the maximum (105) scores of this questionnaire meant no impact of the disease on patient's various aspects of quality of life and great impact of the disease on patient's various aspects of quality of life, respectively. Therefore, the higher the score obtained in this questionnaire, the greater the impact of the disease on quality of life. Zero represents the best case and five is indicative of the worst case. Having a higher reliability and validity compared to other existing questionnaires, Minnesota Quality of life questionnaire is a very credible and specific tool to measure quality of life in patients with heart failure, which was developed by Rector in 1984, in order to determine the effect of treatment on quality of life in patients with heart failure at the University of Minnesota, the US. In the study conducted by Rector, the reliability of this tool was reported as $94 \%$ (18). In a study carried out by Mohammadi on the Iranian population, reliability and validity of this questionnaire were obtained as 91\% and 93\%, respectively
(19). In this study with using Cronbach's alpha coefficient, the reliability of this questionnaire was measured as 0.81 .

In order to assess the adaptation level of patients, an author-made questionnaire based on adaptation dimensions of the Roy model was developed. This questionnaire consisted of 55 items in four dimensions of physiology (24 items), self-perception (13 items), role playing (10 items), and independence-dependence (8 items). Each item was scored based on Likert's five-point scale. Items of physiologic dimension are about activity, sleep and relaxation, nutrition, excretion, circulation and oxygenation, fluids, electrolytes and endocrines. In self-perception dimensions, items dealt with subjective self, objective self and self in relation to others. Items of role playing dimension were about person's expectations. In this study with using Cronbach's alpha coefficient, the reliability of this questionnaire was measured as 0.84 .

\subsection{Methods}

Using the Roy questionnaire and answers of patients to the questions, the number of maladaptive behaviors and their drivers were determined in four dimensions. For this purpose, answers are divided to two categories of positive and negative, then positive answers are regarded as adaptive behaviors and negative answers or those that are partly negative are considered as maladaptive behaviors. In addition to interviews, observation and measurement were also used in this form for determining maladaptive behaviors. In this questionnaire, the minimum and the maximum scores in the physiologic, self-perception, role playing, dependence-independence dimensions were 24 and 120,13 and 65, 10 and 50, and 8 and 40, respectively. In each dimension, higher scores represent better adaptation of patients to their disease.

To assess the validity, the questionnaire was given to ten professors of Faculty of Nursing and Midwifery at Ahvaz Jundishapur University of Medical Sciences and their comments were applied to the questionnaire. Reliability of this questionnaire was also obtained by the test-retest $\operatorname{method}(\mathrm{r}=0.75)$.

\subsection{Statistical Analysis}

The collected data and information were statistically analyzed using descriptive statistics (frequency, mean and standard deviation) and analytical statistics in SPSS-22 software. Normal distribution of data was analyzed using onesample Kolmogorov-Smirnov test (non-parametric test). In addition, t-test was used to compare the quality of life and adaptation between males and females. Level of significance in this study was considered as 0.05. 


\subsection{Ethical Considerations}

Ethical considerations were taken into account in accordance with the Helsinki law. Objectives of the study were explained to patients and they were given the opportunity to ask their questions. A written informed consent was obtained from all patients. In addition, all patients were assured that their information will be kept confidential and only be used in the present study.

\section{Results}

In this study, 76 patients with heart failure were selected as the sample, with a mean age of $55.14 \pm 9.26$. The majority of participants were male (69.7\%), married (97.4\%), burgher (81.6\%). and retired (35.5\%). In addition, most of patients had an education degree under high school diploma (86.6\%), annual income of 400,000 $1,500,000$ Tomans (35.5\%), and a history of the disease more than one year (97.4\%). The average duration of heart failure in the studied patients was $3.56 \pm 1.97$ (Table 1 ).

Table 2 shows the mean scores of various dimensions of quality of life. According to this table, the highest mean belonged to the physical dimension (32.97 \pm 6.89$)$. This means that this disease has put the greatest negative impact on physical dimension of quality of life. In addition, the lowest mean was related to the mental dimension (7.72 $\pm 6.06)$. This means that this disease has put the least negative impact on mental dimension of quality of life.

In Table 3, mean scores of adaptation dimensions based on the Roy adaptation model are presented. According to this table, the highest and the lowest mean adaptation belonged to the physical dimension $(84.06 \pm 12.7)$ and independence-dependence dimension $(28.71 \pm 5.54)$, respectively.

Table 4 provides a comparison between males and females in terms of dimension of quality of life. As it can be observed in this table, there is a significant difference between males and females in physical and mental dimensions of Minnesota quality of life questionnaire, with lower scores for females in both dimensions. Although the sum of mean scores of dimensions of quality of life was higher in females, this difference was not statistically significant.

Table 5 shows the comparison between males and females in terms of adaptation dimensions. According to this table, different dimensions of adaptation are the same in males and females and there is no significant difference between them.

\section{Discussion}

The results showed that heart failure leaves the greatest and the least negative impact on physical and mental dimensions of quality of life, respectively. In addition, the highest and the lowest mean adaptation belonged to physical and independence-dependence dimensions.

The study results showed that the highest frequency of subjects in terms of gender was related to males (69.7\%) and the incidence of heart failure in males was higher than females. This is inconsistent with the findings of Ahmadi et al. (6). The results of Heydari and Vaghee (10) indicated higher prevalence of heart disease in males than females, which is consistent with the present study. In terms of education, the majority of patients (86.8\%) had a low literacy level. In this regard, Yousefi et al. stated that education level is a factor affecting the incidence of heart failure and believed that this factor can affect quality of life, so it needs to be seriously taken into account (20). In a study conducted by Borhani et al. most patients with heart failure had an education degree under high school diploma, which is consistent with the findings of the present study (1).

The results showed that heart failure leaves the greatest and the least negative impact on physical and mental dimensions of quality of life, respectively. The results of Mohammadi et al. (2010) in Karaj corroborated this finding (19). In a study conducted by Yousefi et al. (2011) in Kerman, similar results were obtained (20). Decreased physical performance was caused by fatigue and decreased left ventricular ejection fraction, while depression probably reduced the optimal self-care behaviors and exacerbated the symptoms and severity of disease. This ultimately reduces patients' quality of life.

In general, the results of this study showed that patients with heart failure in Shushtar do not have a good quality of life. The findings of Mohammadi Zeighami and Shahparian, Yousefi et al. and Abedi et al. also indicated that patients with heart failure have a poor quality of life (19-21). Chronic and debilitating nature of this disease, heavy costs of frequent hospitalizations and treatments, impairment in performing daily activities and fatigue, dependence on others and loss of independence for self-care measures, sexual problems, and difficulty in performing jobs and social duties are factors, which can affect the quality of life of patients with heart failure (22).

In the present study, the findings suggested poor adaptation of patients to their disease. The results of a study conducted by Khalilzadeh et al. also indicated weak adaptation of heart failure patients to their disease (16).

The study findings indicated that nursing theories can be effective and helpful in identification of maladaptive behaviors and trying to correct them. It seems that training of these theories only in postgraduate courses in Iran does not ensure their application. This requires familiarity of bachelor's students with these theories. Evidence sug- 
Table 1. Demographic Variables of Participants ${ }^{\mathrm{a}}$

\begin{tabular}{|c|c|}
\hline Demographic Variables & Total patients ( 76 participants) \\
\hline Age & $55.14 \pm 9.26$ \\
\hline Gender(Male) & $53(69.7)$ \\
\hline Marital status (married) & $74(97.4)$ \\
\hline \multicolumn{2}{|l|}{ Education level } \\
\hline Below diploma & $66(86.8)$ \\
\hline diploma or higher & $10(13.2)$ \\
\hline \multicolumn{2}{|l|}{ Occupation } \\
\hline Employment & $21(27.6)$ \\
\hline Unemployment & $5(6.6)$ \\
\hline Retired & $27(35.5)$ \\
\hline Housekeeper & $23(30.3)$ \\
\hline \multicolumn{2}{|l|}{ Income per month, Rials } \\
\hline$<4000000$ & $16(21.1)$ \\
\hline $400-8,000,000$ & $15(19.7)$ \\
\hline $800-15,000,000$ & $27(35.5)$ \\
\hline$>15,000,000$ & $18(23.7)$ \\
\hline \multicolumn{2}{|l|}{ Residences } \\
\hline Urban & $62(81.6)$ \\
\hline Rural & $14(18.4)$ \\
\hline \multicolumn{2}{|c|}{ History of heart failure disease } \\
\hline Less than a year & $2(2.6)$ \\
\hline More than a year & $74(94.4)$ \\
\hline
\end{tabular}

${ }^{\mathrm{a}}$ Values are expressed as mean \pm standard deviation or No.(\%).

Table 2. Mean of Different Dimensions of Quality of Life [Minnesota]

\begin{tabular}{lc}
\hline Dimensions & Mean \pm Standard Deviation \\
\hline Physical & $32.97 \pm 6.89$ \\
Spiritual-Mental & $7.72 \pm 6.06$ \\
Social-Economic & $15.92 \pm 6.22$ \\
Total of all dimensions & 56.61 \\
\hline
\end{tabular}

Table 3. Mean of Different Dimensions of Adaptation (on the basis of Roy adaptation model)

\begin{tabular}{lc}
\hline Dimensions & Mean \pm Standard Deviation \\
\hline Physiologic Needs & $84.06 \pm 12.7$ \\
Self-Concept & $44.98 \pm 8.42$ \\
\hline Role Function & $39.56 \pm 6.75$ \\
Independence/Interdependence & $28.71 \pm 5.54$ \\
\hline
\end{tabular}

gests that the permanent position of patient consultation in Iran's health system has not been taken into account as it should be. Based on the clinical knowledge and with the support of nursing theories that deal with psychological aspects of patients, nurses can play an effective role in counseling and training of patients. According to the Roy care model, nurses can help patients adapt with their disease conditions.

The results also revealed that there is a significant difference between males and females in terms of physical and mental dimensions of quality of life, with lower scores for females in both dimensions. The findings of Abedi et al. 
Table 4. Comparison of Mean of Quality of Life Dimensions Between the two Genders ${ }^{\mathrm{a}}$

\begin{tabular}{|c|c|c|}
\hline Dimensions/Gender & Mean \pm Standard Deviation & P Value \\
\hline Physical & & $0.037^{b}$ \\
\hline Males & $15.71 \pm 8.89$ & \\
\hline Females & $20.43 \pm 8.93$ & \\
\hline Spiritual-Mental & & $0.007^{b}$ \\
\hline Males & $6.77 \pm 5.45$ & \\
\hline Females & $10.73 \pm 6.31$ & \\
\hline Social-Economic & & 0.457 \\
\hline Males & $16.35 \pm 6.24$ & \\
\hline Females & $15.21 \pm 5.78$ & \\
\hline Total of all dimensions & & 0.070 \\
\hline Males & $38.66 \pm 17.19$ & \\
\hline Females & $46.37 \pm 5.78$ & \\
\hline
\end{tabular}

${ }^{\text {a } I n-d e p e n d e d ~ t-t e s t ~ w a s ~ u s e d . ~}$

${ }^{\mathrm{b}}$ Statically difference $(\mathrm{P}<0.05)$

Table 5. Comparison of Mean of Adaptation Dimensions Between the two Genders ${ }^{\mathrm{a}}$

\begin{tabular}{|c|c|c|}
\hline Dimensions/Gender & Mean \pm Standard Deviation & P Value \\
\hline Physiologic Needs & & 0.376 \\
\hline Males & $84.92 \pm 12.18$ & \\
\hline Females & $82.08 \pm 13.98$ & \\
\hline Self-Concept & & 0.187 \\
\hline Females & $43.04 \pm 9.36$ & \\
\hline Role Function & & $0.064^{\mathrm{b}}$ \\
\hline Males & $40.50 \pm 7.08$ & \\
\hline Females & $37.39 \pm 5.45$ & \\
\hline Independence/Interdependence & & 0.413 \\
\hline Males & $29.05 \pm 6.26$ & \\
\hline Females & $27.91 \pm 3.34$ & \\
\hline Total of all dimensions & & 0.123 \\
\hline Males & $200.32 \pm 25.14$ & \\
\hline Females & $190.43 \pm 25.87$ & \\
\hline
\end{tabular}

${ }^{\text {a }}$ In-depended t-test was used.

${ }^{\mathrm{b}}$ Statically difference $(\mathrm{P}<0.05)$.

also showed that females have a lower physical functioning and mental health than males (21).

The results of this study also showed that different dimensions of adaptation are the same in males and females and there is no significant difference between them. The results of a study conducted by Khoshtarash et al. also indi- cated that there is no significant relationship between demographic variables and self-care behaviors (5).

This study also had some limitations: firstly, participants were enrolled from only one hospital and secondly, this study was performed in one city of Iran, and therefore, generalizability was limited. 


\subsection{Conclusion}

The present study showed that quality of life and adaptation are in a weak status among the studied patients with heart failure. By taking appropriate measures and training programs based on the Roy adaptation model, nurses can help these patients improve their quality of life and level of adaptation to their own disease. The findings also indicated that heart failure leaves the greatest negative impact on physical dimension and the lowest mean of adaptation belongs to independence-dependence dimension. Thus, these two dimensions should be seriously taken into account in future planning.

\section{Acknowledgments}

The authors would like to thank all patients, who participated in this study with full consent and also Mohsen Jamali and Fatemeh Jorfi, dear cardiovascular specialists in Shushtar, without the assistance and cooperation of whom this research would not have been completed.

\section{Footnote}

Authors' Contribution: Study concept and design: Shahram Baraz; acquisition of data: Akram Mansouri. Analysis and interpretation of data: Akram Mansouri, Mojtaba Miladinia, and Amal Saki Malehi; drafting of the manuscript: Mojtaba Miladinia and Shahram Baraz; critical revision of the manuscript for important intellectual content: Mojtaba Miladinia and Shahram Baraz. Statistical analysis: Amal Saki Malehi; administrative, technical and material support: Shahram Baraz and Nasrin Elahi. Study supervision: Shahram Baraz and Nasrin Elahi.

\section{References}

1. Borhani F, Khoshab H, Abbaszadeh A, Rashidinejad H, Mohammadi E. Study of the effect of partnership care model on the quality of life in patients with heart failure. J Crit Care Nurs. 2012;5(1):43-8.

2. Hjelm CM, Brostrom A, Riegel B, Arestedt K, Stromberg A. The association between cognitive function and self-care in patients with chronic heart failure. Heart Lung. 2015;44(2):113-9. doi: 10.1016/j.hrtlng.2014.12.003. [PubMed: 25682390].

3. Riegel B, Weaver TE. Poor sleep and impaired self-care: towards a comprehensive model linking sleep, cognition, and heart failure outcomes. Eur J Cardiovasc Nurs. 2009;8(5):337-44. doi: 10.1016/j.ejcnurse.2009.06.003. [PubMed:19679510].

4. Filipe MD, Meijers WC, Rogier van der Velde A, de Boer RA. Galectin3 and heart failure: prognosis, prediction \& clinical utility. Clin Chim Acta. 2015;443:48-56. doi: 10.1016/j.cca.2014.10.009. [PubMed: 25446877]
5. Khoshtarash M, Momeni M, Ghanbari A, Salehzadeh A, Rahmatpour P. Self-care behaviors and related factors in patients with heart failure reffering tomedical \& educational center of heart in Rasht.. Holistic Nursing and Midwifery Journal. 2013;23(1):22-9.

6. Ahmadi A, Soori H, Mobasheri M, Etemad K, Khaledifar A. Heart failure, the outcomes, predictive and related factors in Iran. J Mazandaran Univ Med Sci. 2014;24(118):180-8.

7. Conley S, Feder S, Redeker NS. The relationship between pain, fatigue, depression and functional performance in stable heart failure. Heart Lung. 2015;44(2):107-12. doi: 10.1016/j.hrtlng.2014.07.008. [PubMed: 25576085].

8. Hallas CN, Wray J, Andreou P, Banner NR. Depression and perceptions about heart failure predict quality of life in patients with advanced heart failure. Heart Lung. 2011;40(2):111-21. doi: 10.1016/j.hrtlng.2009.12.008. [PubMed: 20561889].

9. Graven LJ, Grant JS. Coping and health-related quality of life in individuals with heart failure: an integrative review. Heart Lung. 2013;42(3):183-94. doi: 10.1016/j.hrtlng.2012.12.002. [PubMed: 23312147].

10. Heydari A, Vaghee S. The role of Self-concept Mode of Roy's Adaptation Model on adherence of diet regimen in heart failure patients. Horizon Med Sci. 2012;17(4):18-24.

11. Miladinia M, Baraz S, Shariati A, Malehi AS, Amadzadeh A. Relationship Between Chronic Pain and Quality of Life in Patients With Acute Leukemia Undergoing Chemotherapy. Jundishapur J Chron Dis Care. 2015;4(3).

12. Baraz S, Shahbazian HB, Miladinia M, Zarea K. Video Training Programs and the Quality of Life of Patients With Type II Diabetes. Jundishapur J Chron Dis Care. 2015;4(4).

13. Baraz S, Miladinia M, Mosavinouri E. A Comparison of Quality of Life between Adolescences with Beta Thalassemia Major and their Healthy Peers. Int J Pediatr. 2016;4(1):1195-204.

14. Naeim Hassani S, Tabiee S, Saadatjoo SA, Kazemi T. The effect of an educational program based on Roy adaptation model on the psychological adaptation of patients with heart failure. Modern Care J. 2014;10(4):231-40.

15. Shojaei F. Quality of life in patients with heart failure. $J$ Hayat. 2008;14(2):5-13.

16. Khlilzade H, Nanbakhsh J, Yaghobi M. Results of adaptation of heart failure patients with Problems caused by the disease. J Nurs Midwifery Urmia Univ Med Sci. 2008;4(4):154-60.

17. Bakan G, Akyol AD. Theory-guided interventions for adaptation to heart failure. J Adv Nurs. 2008;61(6):596-608. doi: 10.1111/j.13652648.2007.04489.x. [PubMed: 18302601].

18. Mohamadi Zeighami SH, Shahparian M. Factors in sleep problems with male systolic heart failure patients.J Health Psychol. 2011;1(1):13557.

19. Mohammadi Zeighami S, Shahparian M. Quality of Life (Qol) and Some Factors Related in Males with Heart Failure in Karaj and Shahriar Social Security Hospitals (2010). J Gorgan Faculty Nurs Midwifery. 2012;8(2):1-13.

20. Yousefi P, Sabzevari S, Mohammadalizade S, Haghdoost AA. Study of quality of life in heart failure hospitalized patients in Kerman medical university hospital in 2008. Life Sci J. 2011;6(21):59-67.

21. Abedi HA, Alipour MY, Abdeyazdan GH. Quality of Life in heart failure patients referred to the Kerman outpatient centers. Journal of Shahrekord University of Medical Sciences.J Shahrekord Univ Med Sci. 2011;13(5):55-63.

22. Afrasiabifar A, Karimi Z, Hassani P. Roy's Adaptation Model-Based Patient Education for Promoting the Adaptation of Hemodialysis Patients. Iran Red Crescent Med J. 2013;15(7):566-72. doi: 10.5812/ircmj.12024. [PubMed: 24396575]. 